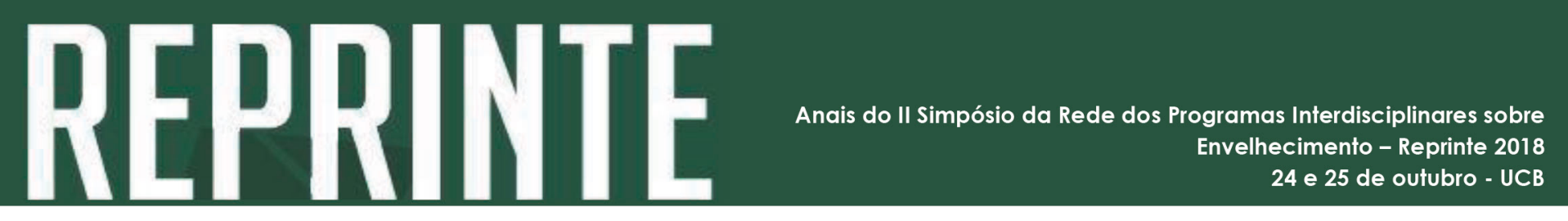

http://dx.doi.org/10.5335/rbceh.v16i1.9921

\title{
30) Extensão da teoria da seletividade socioemocional a idosos usuários do Facebook
}

\author{
Tássia Monique Chiarelli'; Samila Sathler Tavares Batistoni²
}

\section{Resumo}

As novas Tecnologias de Informação e Comunicação ( $\mathrm{TIC}^{\prime} \mathrm{s}$ ) trazem novos desafios às teorias clássicas sobre relações sociais na velhice. Objetivos: Seguindo os pressupostos da Teoria da Seletividade Socioemocional (TSSE), o presente estudo investigou o quanto esses se estendem às relações sociais de idosos mediadas pela utilização do Facebook. Métodos: Foram entrevistados 130 idosos recrutados em serviços públicos de acesso à internet na cidade de São Paulo (82,3\% feminino, $M=67,9$ anos de idade, $M=12$ anos de estudo) usuários do Facebook há pelo menos um ano e com no mínimo 30 contatos estabelecidos na rede. Foram levantados dados sociodemográficos, de uso do Facebook (frequência de utilização, tamanho da rede, senso de autoeficácia, qualidade dos contatos) e referentes a construtos centrais à TSSE (escala de Perspectiva de Tempo Futuro - PTF e Satisfação com a Vida). Para testar as relações entre as variáveis do estudo e satisfação com a vida foi utilizada a análise de equações estruturais para variáveis manifestas (Path Analysis). Resultados: Foram encontradas associações diretas e mediadas por PTF entre idade e satisfação com a vida, e relações diretas entre idade e tamanho das redes sociais, conforme predito pela Teoria. Indicadores de seletividade socioemocional, como redução no tamanho das redes e proximidade emocional não foram associados a satisfação com a vida. Conclusão: Os dados sugerem que as relações sociais via Facebook pressupõe a atuação de um conjunto diferenciado de metas sociais e de mecanismos adaptativos associados à satisfação com vida na velhice.

Palavras-chave: Teoria da Seletividade Socioemocional; Relações Sociais; Idosos; Facebook.

\section{Introdução}

As novas Tecnologias de Informação e Comunicação (TIC's) trazem novos desafios às teorias clássicas sobre relações sociais na velhice.

1 Mestre no Programa de Pós-Graduação em Gerontologia, Escola de Artes, Ciências e Humanidades da USP. Endereço para correspondência: Avenida Arlindo Béttio, 1000 - Cep 03828000 - São Paulo - SP, Brasil. Email: tassiamonique@ usp.br

2 Professora do Programa de Pós-Graduação em Gerontologia, Escola de Artes, Ciências e Humanidades da USP. Email: samilabatistoni@usp.br 


\section{Objetivos}

Seguindo os pressupostos da Teoria da Seletividade Socioemocional (TSSE), o presente estudo investigou o quanto esses se estendem às relações sociais de idosos mediadas pela utilização do Facebook.

\section{Métodos}

Foram entrevistados 130 idosos recrutados em serviços públicos de acesso à internet na cidade de São Paulo (82,3\% feminino, $\underline{\mathrm{M}}=67,9$ anos de idade, $\underline{\mathrm{M}}=12$ anos de estudo) usuários do Facebook há pelo menos um ano e com no mínimo 30 contatos estabelecidos na rede. Foram levantados dados sociodemográficos, de uso do Facebook (frequência de utilização, tamanho da rede, senso de autoeficácia, qualidade dos contatos) e referentes a construtos centrais à TSSE (escala de Perspectiva de Tempo Futuro - PTF e Satisfação com a Vida). Para testar as relações entre as variáveis do estudo e satisfação com a vida foi utilizada a análise de equações estruturais para variáveis manifestas (Path Analysis).

\section{Resultados}

Foram encontradas associações diretas e mediadas por PTF entre idade e satisfação com a vida, e relações diretas entre idade e tamanho das redes sociais, conforme predito pela Teoria. Indicadores de seletividade socioemocional, como redução no tamanho das redes e proximidade emocional não foram associados a satisfação com a vida.

\section{Conclusão}

Os dados sugerem que as relações sociais via Facebook pressupõe a atuação de um conjunto diferenciado de metas sociais e de mecanismos adaptativos associados à satisfação com vida na velhice.

\section{Extension of the theory of social-emotional selectivity for elderly Facebook users}

Keywords: Socio-emotional Selectivity Theory; Social relationships; Seniors; Facebook. 